\title{
ENERGY REQUIREMENT OF THE MILITARY PERSONNEL
}

\author{
Nikolay NICHEV \\ "Vasil Levski” National Military University, Veliko Tarnovo, Bulgaria \\ nicheff@gmail.com
}

\begin{abstract}
The energy requirements of the military personnel are the result of the carried out in $X X$ century researches about the energy consumption and the nutrition of servicemen and the concepts for using of the military units at that time.

The study makes an analysis and summary of issues related to the energy consumption of the military personnel in field trainings, influence of the mission and environmental conditions on the energy requirement of the military personnel and energy requirements of women in the army.
\end{abstract}

\section{Keywords: energy requirement, nutrition, military personnel}

\section{Introduction}

The exact determination of the energy requirements of the military personnel is linked with the implementation of scientifically grounded approaches for calculation of the total energy requirement. Each vital, work or daily human activity is connected with consumption of energy, which is supplied by the organism by means of dissolving the received nutrient substances. The researchers divide the methods for calculation of the daily energy requirement into two major groups: laboratory and calculative methods.

The laboratory methods comprise the thermal and the respiratory calorimetry. The first method is based on the exact measuring of the heat, released by the body, whilst the second is grounded on the consumption of oxygen and on the exhaled carbon dioxide. The exhaled carbon dioxide can be measured through implementation of the "doublylabeled water" method. This method is based on the measuring of the heart capacity (the warmth dilution) and the difference between the oxygen concentration in the arterial and the mixed venous blood. The methods of nutrient energometry are grounded on the laboratory analysis of the nutrient value of the taken food and of the unassimilated part of food or on calculating of the energy value of the taken food and weight control during a particular time period. Under the method of pulse tachometry using a special device pulse tachometer, the pulse frequency is being measured during the performance of various physical activities and the results are transformed into calories.

The calculative methods are based on the basic metabolism and on ratios of physical activity. Under these methods the basic metabolism by means of formulas, grounded on ratios, sex, weight, age and height are determined separately. The sum total of the obtained values gives the value of consumption for the basic metabolism. To this value of consumption for basic metabolism are added the energy consumption for assimilation of food and the energy consumption for physical load during the active part of the day. By the 
table-chronometry method the spent on a certain activity time is measured exactly. The obtained data permit to determine the daily energy consumption of the person, using tables of the energy consumption for different kinds of activities. First the time expenditure on daily activities of a certain person is measured, fixing their duration.

\section{The energy consumption of the military personnel usually exceeds the energy requirement of the civilian}

Most of the contemporary military researches of the energy consumption have examined soldiers, situated in training camps [2] or participating in specific events, such as: parades, military trainings and others, which usually comprise from 3 up to 10 days of continuous training. During the field training usually military rations are being consumed, and the servicemen sleep in tents or outdoor without shelter. Overall, during preparation for battle missions or while tactical trainings at terrain are conducted, the servicemen are under bigger physical pressure, than when being trained at the permanent dislocation stations. The training at the garrison normally includes training during the day, the usage of the military infrastructure for accommodation and stationary feeding in canteens.

In the researches, in which the energy requirements of the military personnel had been measured, these requirements vary from $2341 \mathrm{kcal} /$ daily for women, occupying administrative positions [1] up to 7118 $\mathrm{kcal} /$ daily for marines, participating in mountain military training [8]. The general measuring of the energy requirement of the whole male military personnel account for average $4609 \pm 645 \mathrm{kcal} /$ daily for all activities and all military specialties during an average measuring period of 12,2 days. These values are approximately $38 \%$ higher than the average general energy requirement for 92 civilian men at the age between 18 and 39 years, which are averagely $3344 \pm 740 \mathrm{kcal} /$ daily [3].
The general energy requirements for female military personnel $(\mathrm{N}=77,2842 \pm 621$ $\mathrm{kcal} /$ daily, average monthly measuring period of 8,8 days (range 2,25-14 days) are approximately $17 \%$ higher than those of the women from civilian society at the age between 18-39 years and average values of energy requirement of $2436 \pm 1051$ $\mathrm{kcal} /$ daily [3].

Comparing the energy requirements of the civilian professions and the professional military personnel, we must take into account the fact, that usually the military researches are directed to examination of the energy requirement during field and tactical trainings, which have limited duration [5, 6]. Also upon some sporting events, the field trainings often result in higher energy requirements, than those of the general civilian population, because of the extended working days and of the specific character of the activities [11]. The civilian personnel, occupied in hard physical work, such as: firemen, metalworkers and others, also demonstrate higher levels of daily energy requirements. The researches show, that some servicemen have an energy requirement, comparable to that of the civilian professions, although most servicemen exceed these levels.

\section{Energy requirement of the combat and support units}

The energy requirements of the soldiers from combat units and of soldiers from the supporting units are examined by different researches. The soldiers from the battle units, training at the permanent dislocation stations, consume approximately $19 \%$ more energy, than the supporting units. We must take into account also the fact, that the soldiers from the forces for special operations often have higher body mass, than the other soldiers and thus the difference is only $5 \%$, in case the energy requirement is expressed in kilogram of the body weight [14]. 


\section{Energy requirement at field trainings on the terrain}

The general energy requirements of the servicemen, participating in field trainings on the terrain can be quite high. To field trainings on the terrain belong: tacticalcombatant training; tactical special training; tactical training; tactical case; group training at spot (with or without elements of commanding-staff training); trainings (staff and special); trainings with or without combatant shooting; combatant shooting with real missile launchings; flying tactical trainings; flying trainings; field preparation at a specialized firing ground; field camp and others $[9,10]$. The total energy requirements of the rangers from the United States, participating in field training, are averagely $5185 \mathrm{kcal} /$ daily [14].

Field trainings on the terrain usually have short duration and are intended on increasing of the field endurance and training competences of the military personnel. They are conducted without interruptions, comprising the whole unit with their regular armament and equipment and communication devices, whereat training tasks are being exercised under conditions, which are to the highest degree close to the real conditions.

The field trainings on the terrain are characterized with the implementation of simulators, which simulate the actions of the opponent party; work under complicated psychological conditions and high levels of psychological stress, characterized with high responsibility for each taken decision and performed action; genuine daily and/or night combatant shootings including all sorts of weapons and systems; practical solving of such tasks, as surviving, engineering equipment; taking cover, defensive tactics, counteroffensive and retreat; limited time for sleep and rest and others.

5. Influence of the mission and environmental conditions on the energy requirement of the military personnel
5.1. Energy requirement under hot climatic conditions

The analysis of the available literature imposes the conclusion, that generally the high temperature of the environment influences insignificantly on the daily energy requirements of the military personnel. A study, carried out in the desert shows, that the artillery units consume averagely $4108 \mathrm{kcal} /$ daily under average daily air temperature of $20.6^{\circ} \mathrm{C}$. Similar total energy requirements (3941 kcal/daily) are observed for the infantry units in Israel, where the temperatures vary from 23 up to $31^{\circ} \mathrm{C}$. The Royal Australian Air Forces in North Australia consume about 3702 $\mathrm{kcal} /$ daily, at temperatures varying from 24 to $33{ }^{\circ} \mathrm{C}$, and the performed tasks are linked with guard and transport support of an airport.

The comparison between the energy requirements of the artillery, of the infantry and of the ground units from the Air Forces show, that the general energy requirements are similar to the values, observed under cooler conditions $(4099 \mathrm{kcal} /$ daily for training at the permanent dislocation station, 3346 and $3568 \mathrm{kcal} /$ daily for everyday activities of the supporting units). One of the reasons for that, roots in the fact, that the servicemen perform their obligations more efficient in hot, dry and clear days. The energy requirements are connected mainly with the sort and the duration of the activities, which are being performed, not with the hot meteorological conditions.

\subsection{Energy requirements in winter and under cold climatic conditions}

Hoyt and team consider that the general energy requirement of the military personnel increases in winter and under cold climatic conditions. In the examination of the American marines in cold weather (under temperatures of the environment from -10 up to $5{ }^{\circ} \mathrm{C}$ ), average energy requirements of $5398 \mathrm{kcal} /$ daily are observed [7]. The general energy requirements had been around 4156 
$\mathrm{kcal} /$ daily in warm weather (under temperatures of the environment from 9 up to $31{ }^{\circ} \mathrm{C}$ ) for the same course at the same place, under analogical general physical and mental pressure. The examination data suppose that the higher energy requirement for the winter course is connected with a longer and with higher physical pressure working day, than the working day under warmer climatic conditions.

The examination of the energy requirement of the military personnel [14] establishes that at work in cold environment the weight of the winter clothing can increase the energy requirements by $16 \%$, compared to the desert clothing and by $8 \%$, compared to the moderate clothes. The positioning of the weight of the clothing or of the equipment also has influence on the general energy requirements. For example, during movement, the wearing of heavy boots increases the energy requirement to bigger extent, than the wearing of the boots in the haversack.

In carried out examinations at extremely cold environments (under average daily temperatures of $-25{ }^{\circ} \mathrm{C}$ ), the energy requirement levels are averagely by $20 \%$ higher than those, observed at trainings of soldiers in moderate climatic conditions. However these examinations additionally illustrate the high levels of energy requirements, which can be reached by the servicemen in cold climatic conditions because of the tough terrain. The general energy requirements increase significantly under ice and snow and when using or wearing of specialized winter equipment, such as snow-shoes or skis, which can add up to $5 \mathrm{~kg}$ weight, compared to the regularly worn equipment. The energy requirements can increase by up to $30 \%$ when moving over stamped snow and by up to $50 \%$ when moving in deep snow, in comparison to the measured values for unpaved road.

The available data, which allow comparisons between the energy requirement under cold climatic conditions and under moderate conditions, sustain the conclusion, that training under cold conditions increases the daily energy requirement. In case of missing snow cover and frozen areas of the terrain, the weight of the additional clothing and equipment, shivering and other body motions caused by the low temperatures are the most probable reasons for the increased energy requirements under cold climatic conditions.

The hardly accessible terrain, the thickness of the snow cover and the slippery surface contribute to the increasing of the energy requirement. Some actions are more difficult to perform at winter; the biomechanical inefficiency additionally increases the total energy expenditures under cold climatic conditions in comparison to the moderate or hot climatic conditions.

\subsection{Energy requirement at high altitude}

The energy requirements of the military personnel increase in result of working at high altitudes. The most significant factor, which increases the energy requirements of the servicemen and is directly linked to the altitude, is the insufficient supply with oxygen of the whole organism - hypoxia. Further factors, increasing the energy requirements, are: the wearing of specialized equipment, strongly rugged terrains and additional clothing.

The servicemen from the American Army, located in Potosi, Bolivia at 3500-4050 m altitude, have had an average daily energy requirement of $3535 \mathrm{kcal}, 10$ days long, during the construction of the infrastructure [4]. These values are a little bit higher than the general energy requirements of 3463 $\mathrm{kcal} /$ daily for servicemen from the engineering units, performing similar activity at a sea area [13].

In his research Tharion and his team prove, that the military training, conducted at high altitudes doesn't have significant influence on the energy requirement. The increased energy expenditures are due to the influence of cold, to the difficult to cross terrain and 
the movement carrying additional equipment. They consider that the increased energy requirement has purely physiological explanations. The acclimatization at high altitudes increases the main speed of metabolism by from 7 up to $17 \%$ at least during the first two or three days of stay under such conditions. Another physiological reason for the increased expenditures of energy is the reduced ability to sleep.

\section{Energy requirements of women in the army}

Just a few studies had evaluated the energy requirements of the female military personnel, in order to determine if they differ from those of the male servicemen. The general energy requirement of the women is smaller than that of men, because overall women possess lower body mass and the scope of the performed tasks is less physically burdensome. Other possible reasons include changes in the menstruation cycle, pregnancy or lactation.

A number of researches impose the conclusion, that the general energy requirement of women is lower than that of men, but after considering the body mass it becomes visible that female military personnel consume approximately the same quantity of energy as male servicemen.

The differences between the energy requirements of the men and of women are not resulting entirely from the differences of the body mass, connected with the gender. When the general levels of physical activity are relatively moderate, the energy requirement for the main metabolism represents a bigger share of the total daily energy requirement. For the reason that men usually have bigger body mass, compared to women, their energy requirements for the main metabolism are higher, what results in a higher general energy requirement, including that of the daily energy consumption for $1 \mathrm{~kg}$ of body weight. Low energy consumption for women reflects the same tendency. And to the opposite, in case of high levels of energy consumption for physical load during the whole day, no differences are observed in the average daily energy requirement for $1 \mathrm{~kg}$ of the body weight. The average daily energy requirement of female and male servicemen with the same functional duties and analogical physical activities is shown at Table 1 .

Table 1 Average daily energy requirement of female and male servicemen with the same functional duties and analogical physical activities [14]

\begin{tabular}{|c|c|c|c|c|c|}
\hline Physical activities & 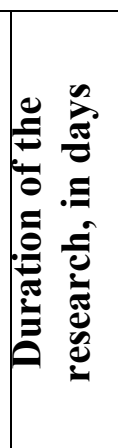 & 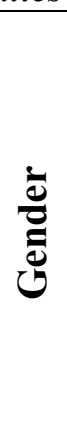 & 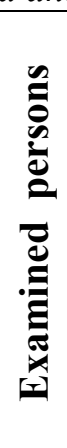 & 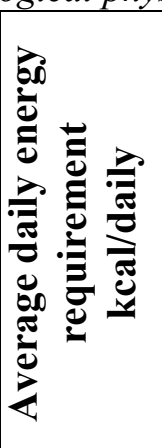 & 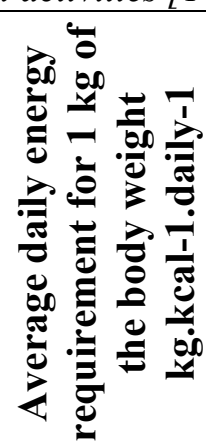 \\
\hline \multirow{2}{*}{$\begin{array}{l}\text { Continued work during the training of } \\
\text { Norwegian rangers }\end{array}$} & \multirow{2}{*}{7} & $\mathrm{M}$ & 6 & 6678 & 93.5 \\
\hline & & $\mathrm{F}$ & 4 & 5597 & 95.7 \\
\hline \multirow{2}{*}{ Field training with intense physical loads } & \multirow{2}{*}{2.25} & $\mathrm{M}$ & 29 & 6129 & 83.0 \\
\hline & & $\mathrm{F}$ & 20 & 4727 & 82.0 \\
\hline \multirow{2}{*}{ Physical training } & \multirow{2}{*}{14} & $\mathrm{M}$ & 20 & 4048 & 56.1 \\
\hline & & $\mathrm{F}$ & 10 & 2378 & 41.1 \\
\hline Administrative activities & 11 & $\mathrm{M}$ & 1 & 2332 & 38.7 \\
\hline
\end{tabular}




\begin{tabular}{|c|c|c|c|c|c|}
\hline Physical activities & 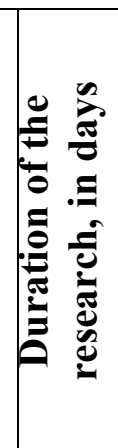 & ঠ் & 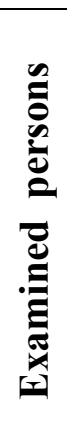 & 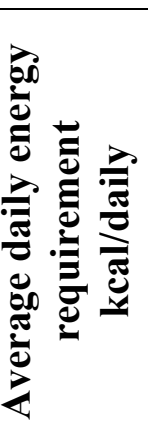 & 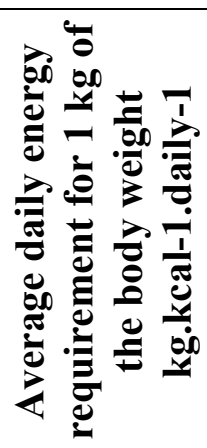 \\
\hline & & $\mathrm{F}$ & 4 & 3709 & 34.3 \\
\hline \multirow{2}{*}{ Medical support } & \multirow{2}{*}{11} & $\mathrm{M}$ & 6 & 3925 & 46.1 \\
\hline & & $\mathrm{F}$ & 10 & 2899 & 47.4 \\
\hline \multirow{2}{*}{ Everyday activities } & \multirow{2}{*}{8} & $\mathrm{M}$ & 9 & 3446 & 43.5 \\
\hline & & $\mathrm{F}$ & 16 & 2776 & 40.9 \\
\hline
\end{tabular}

\section{Conclusions}

The knowledge of the actual energy requirements of the military personnel contributes to determination of the most suitable combination of nutrient products and daily menus for the maintenance of health of the servicemen and for the insurance of the optimal daily activity. It could also assist at the strategic level of Command of the Bulgarian Army in the process of elaboration of new nutrient standards, regulations and rations, which would correspond to the nutrient needs and physiological nutrition norms under different operation conditions and requirements of the environment [12]. The energy requirements at a specific situation grant the proper scientific base for optimizing of the expenditures on food for the physically active military personnel.

\section{References}

[1] Baker-Fulco, C. J., Kramer, F. M., Johnson, J., Lesher, L. L., Merill, E., \& DeLany, J. Dietary intakes of female and male combat support hospital personnel subsisting on meal-focused or standard versions of the meal, ready-to-eat. Natick, MA: United States Army Research Institute of Environmental Medicine, 2002, Technical Report No. T0223. http://www.dtic.mil/get-tr-doc/pdf?AD=ADA406726, visited on 23.10.2017

[2] Bertrandt, J., Kłos, A., Lakomy, R. Assessment of the energy expenditure of soldiers of the Representative Battalion of the Polish Army during three days of drill training as part of preparations for the celebration of the National. Independence Day of November 11th 17. Military Pharmacy and Medicine, Volume V, No. 4, October - December 2012, pp. 17-21

[3] Black, A. E., Coward, W. A., Cole, T. J., \& Prentice, A. M. Human energy expenditure in affluent societies: an analysis of 574 doublylabeled water measurements. European Journal of Clinical Nutrition, 50, 1996, pp.72-92.

[4] Edwards, J. S. A., Askew, E. W., King, N., Fulco, C. S., Hoyt, R. W., DeLany, J. P. An assessment of the nutritional intake and energy expenditure of unacclimatized US Army soldiers living and working at high altitude. Natick, MA: United States Army Research Institute of Environmental Medicine. Technical Report No. T10-91, 1991, http://www.dtic.mil/get-tr-doc/pdf?AD=ADA237450, visited on 13.12.2017 
[5] Glushkov, P. A Study of Nutrition and the Nutritional Status of Servicemen, Assessed on the Basis of Anthropometric Indicators. International conference Knowledge-Based Organization, Volume XXIII No 2, 2017, pp. 298-302

[6] Glushkov, P. Use of Linear Optimization Model in Defining the New Standards for the Preparation of Food for Servicemen in Preparation for Participation in Peacekeeping Operations. International conference Knowledge-Based Organization, Volume XXIII No 2, 2017, pp. 65-70

[7] Hoyt, R. W., Buller, M. J., DeLany, J. P., Stultz, D., Warren, K., Hamlet, M. P. Shantz, D., Matthew, W. T., Tharion, W. J., Smith, P., \& Smith, B. Warfighter physiological status monitoring (WPSM): energy balance and thermal status during a 10-day cold weather US Marine Corps Infantry Officer Course field exercise. Natick, MA: United States Army Research Institute of Environmental Medicine, 2001, Technical Report No. T02-02. http://www.dtic.mil/get-tr-doc/pdf?AD=ADA396133, visited on 03.11.2017

[8] Hoyt, R. W., Jones, T. E., Stein, T. P., McAninch, G. W., Lieberman, H. R., Askew, E. W., \& Cymerman, A. Doubly labeled water measurement of human energy expenditure during strenuous exercise. Journal of Applied Physiology, 71, 1991. pp: 16-22.

[9] N. Nichev. Theoretical foundations of military logistics - organization of logistical support. Vasil Levski National Military University, Veliko Tarnovo, Bulgaria, 2011, p.118

[10] Nichev, N., Methodology of the special military preparation of the logistic units for material supply. Publishing complex of Vasil Levski NMU, V. Tarnovo, 2016, p. 32

[11] Stefanov, N. Analysis of Some of the Applicable Outsourcing Services in the Structures of the Bulgarian Armed Forces. International conference Knowledge-Based Organization, Volume XXIII No 1, 2017, pp. 473-478

[12] Stefanov, N. Analysis of the Use of Outsourcing Services for Maintenance and Repair of the Equipment and Armament Available in the Structures of the Bulgarian Armed Forces. International conference Knowledge-Based Organization, Volume XXIII No 1, 2017, pp. 467-472

[13] Tharion, W. J., Baker-Fulco, C. J., McGraw, S. M., Johnson, W. K., Niro, P., Warber, J. P., Kramer, F. M., Allen, R., Champagne, C. M., Falco, C., Hoyt, R. W., DeLany, J. P., $\&$ Lesher, L. The effects of 60 days of tray ration consumption in Marine combat engineers while deployed on Great Inagua Island, Bahamas. Natick, MA: United States Army Research Institute of Environmental Medicine. Technical Report No. T00-16. 2000, http://www.dtic.mil/get-tr-doc/pdf?AD=ADA376950, visited on 03.11.2017

[14] W.J. Tharion et al. Energy requirements of military personnel. Appetite 44, 2005, pp. 47-65 